\title{
A Teaching Model for Undergraduate Students
}

\author{
Kakyung Ahn ${ }^{1}$ \\ ${ }^{1}$ Faculty, College of General Studies, Seokyoeng University, Korea \\ Correspondence: Kakyung Ahn, Faculty, College of General Studies, Seokyoeng University, Korea. \\ E-mail:kkahn@skuniv.ac.kr
}

Received: April 4, 2018

Accepted: September 28, 2018

Online Published: May 9, 2019

doi:10.5430/ijhe.v8n3p29

URL: https://doi.org/10.5430/ijhe.v8n3p29

\begin{abstract}
Mathematics, along with the need for logic and thinking, is becoming more important in many fields. Therefore, many universities in Korea have opened and operated a college basic math course to improve basic math skills for freshmen in science and engineering. The new generation of digital generation is creative, familiar with cooperation and active. They are already rapidly changing and ready for new education, and education needs a new paradigm to evolve. Flipped Learning is being suggested which is well known as a teaching method which lets students learn the contents they will learn in advance through the advance online video and have a discussion through the team interaction in the main class for them to solve the assignment through the cooperation in a self-initiated way. In this study, we have taken a merit of flipped learning, made a model of Gauss Jordan elimination method in matrix that students cannot easily understand in the lecture. Here, we will introduce a teaching model that combines flipping learning and existing lecture methods.
\end{abstract}

Keywords: e-learning, flipped learning, mathematical model, ICT, gauss Jordan elimination

\section{Introduction}

Mathematics, along with the need for logic and thinking, is becoming more important as the field of use increases. Therefore, many universities in Korea have opened and operated a college basic math course to improve basic math skills for freshmen in science and engineering. However, many universities are suffering from students who avoid or eventually give up mathematics due to the nature of the admission system, which lacks the basic math skills or enables cross-supporting and my university has the same situation. For students who have little foundation for mathematics, math is a subject they do not want to study because it is boring and uninteresting, and more students are giving up math due to the burden of classes (Kim, D.R., 2017).

With the growth of IT technology, the proliferation of various smart devices, and the growth of its users, is changing our lives, and has created a new learning paradigm that has created unprecedented influence in education.

The use of smart devices has enabled users to quickly acquire more information or knowledge and to feel more convenient throughout their lives. As such, education is increasingly turning to using the Internet and smart devices to learn in a way that learners want at any time and place they want instead of staying in a traditional classroom. Accordingly, the Ministry of Education, Science and Technology announced in October 2011 that smart education will be implemented starting from 2015. This paradigm was influenced by 'digital native' that is familiar with the digital environment. For those who are more familiar with digital devices than with books and who are accustomed to multitasking and rapid response amid a flood of web-based information, education in one-way forms is no longer effective. However, education services related to smart learning are still in the beginning stage, and education using these services is not being activated. In response, the study seeks to find a learner-centered alternative to education by proposing a smart learning class model for digital generations based on university design research classes. Using these measures, they want to present ways to address the environmental weaknesses of existing education in classrooms and suburban research areas and enhance the effectiveness of learning through creative self-directed learning.

Today's students, surrounded by multimedia that interacts with various digital devices, have a very different mindset, information processing, and so on than the past students who are familiar with static text and images. According to the National Digital Literacy Survey, compiled by the PISA, South Korea's reading comprehension accounts for the highest percentage in the world. This means that Korean students are already most accustomed to digitalization and 
therefore expect to have a great synergy effect if appropriate smart learning is provided (Seo, B.B., Chea, Y.J., Pan, Y.H., Mai, L.H., 2016).

\section{Background}

Educational consciousness has largely been transformed by needs and needs from two educational perspectives, from a professor-centered objectivism to a learner-centered constructivism. This change is due to a change in the education paradigm, as the human resources award of the era is required differently. In this regard, the Flipped Learning professor learning model, which represents the ICT (Information Communication Technology) based learning environment, is proving its effectiveness and efficiency in terms of educational performance. ICT utilization education is based on basic information communication skills to actively utilize ICT in solving problems in everyday learning (Korea Institute of Education Information, 2002). In other words, it is education that utilizes ICT as an educational medium by integrating it into the curriculum by achieving the goals of teaching and learning in the most effective manner. In ICT utilization training, the meaning of technology can be understood as an optical activity that applies scientific knowledge by performing tasks or solving problems (Aremu, J. O., 2018), including techniques or methods, not just processes or processes, such as hardware and software (Kwon, H.I., 2004). Worldwide, ICT utilization education is moving from teaching how to use computers to applying information and communication to education classes (Altunkaya, H., \& Ates, A., 2018). However, even if ICT is equipped with advanced educational environments, satisfactory classes cannot be conducted without sufficient review and design process of basic factors such as classroom content, learning organization, learning environment, and class type. In this context, the Korea Institute for Educational, Scientific and Information presents the following in terms of ICT education direction. First, ICT utilization education should be diverse and flexible learning activities that maintain the characteristics of learners, away from the limited educational environment centered on classroom and memorized knowledge transfer. Second, plan with learning objectives by exchanging opinions on information search using ICT. It is necessary to create a learning environment that is led by learners in the learning process such as evaluating the results. Third, by directly participating in the process of collecting, analyzing, and compiling new information such as collecting, analyzing, and compiling information using various ICTs, creativity and problem solving must be developed. Fourth, it should be used in conjunction with problem-solving, project learning, situation learning, and cooperative study to help diverse classes so that quality and quantity of teaching can be improved (Lee, S.D.,Park, S.H., Kim, D.K., Kang, S.G., 2010).

\section{e-Learning}

e-Learning is a short for electronic-learning, which means learning based primarily on electronic technology, but usually means learning and learning experiences made using multimedia and network work, or information technology and computer technology. One of the representative uses of ICT in college education is online education based on the Internet, that is e-Learning. e-Learning, which is called as various terms such as cyber classes, virtual lectures, and online classes, is an educational method introduced by major universities, both at home and abroad (Kwon, S.H., Lee, J., Han, S.Y., \& B, S.H., 2012)(Almeqdadi, F., 2018)(Anwar, M. N., 2018).

\section{Flipped learning}

Flipped learning, a true form of e-learning in college, is a form of blended learning that combines technology with classroom lessons (Bergmann, J., \& Sams, A., 2012)(Aremu, J. O., \& Ediagbonya, M., 2018)(Asli, H. N., 2018). In other words, it is a method of conducting 'tasks (discussing online video lectures, etc.) that are based on existing professor-oriented lecture classes in the classroom that apply my own purposes learned at school. At this time, technology is used to improve learning effects. Therefore, flipped learning is seen as an alternative to implementing academic life-oriented classes by changing existing teaching methods. The most important thing in flipped learning is the interaction and significant learning activity in face-to-face classes, which can depend on how classroom classes are designed and operated, rather than simply providing instructional videos. In flipped learning session, a success factor is that how hard students take part in. However, for learners who are used to passive, or who lack self-directed learning skills, flipped learning may add to the learning burden and increase their rejection. 
Table 1. Comparison between general lessons and flipped learning lessons

\begin{tabular}{lll}
\hline General lesson & Division & Flipped learning lesson \\
\hline One-sided class & Classroom & $\begin{array}{l}\text { Interaction between teacher and students, problem } \\
\text { solving, discussion, and debate }\end{array}$ \\
\hline Problem solving, debate & Outside Classroom & \begin{tabular}{l} 
One-way lesson from prior learning materials \\
\hline $\begin{array}{l}\text { Easy to send basic } \\
\text { knowledge }\end{array}$
\end{tabular} \\
\hline Difficulty in-depth study & Weakness & $\begin{array}{l}\text { Enable in-depth study } \\
\text { Reduce the gap between students }\end{array}$ \\
\hline & Preparation burden is high for teacher and students
\end{tabular}

Figure 1. Bishop and Verleger's Flipped Classroom [10]

\section{Teaching Model}

The use of Gauss-Jordan elimination is quite a large part of the problems with the matrix in Linear Algebra (Lee, S.G., Park, K.E., 2016). In particular, students at our university learn this in their first year. There were many students who did not understand elementary row operation during class. So I made a class model using e-learning with multimedia to help students understand. I was also interested in the flipped learning method, so I introduced some of the methods used in the flipped learning. Videos that introduce the content of the elimination method are provided online and provide a description of the video content to help they understand. And made an Matlab m-file which introduce step by step process to find a reduced row echelon form and added a way for students to check the process again through their computers. All paragraphs must be justified alignment. With justified alignment, both sides of the paragraph are straight (Bastug, G., 2018)(Caifen, W., Hailun, F., \& Rongrong, C., 2018)(Castro, M., 2018).

The teaching model consists of four steps.

Step 1: Students have studied the video materials provided and the materials that explained the video before class.

Step 2: Make a group of two students and explain to each other about the materials provided in class.

Step 3: The part that does not understand improves the understanding level through questions after group activity.

Step 4: Run Marlab m-file and check the algorithm to understand the contents.

Next, we present the Matlab m-file and its implementation process. 

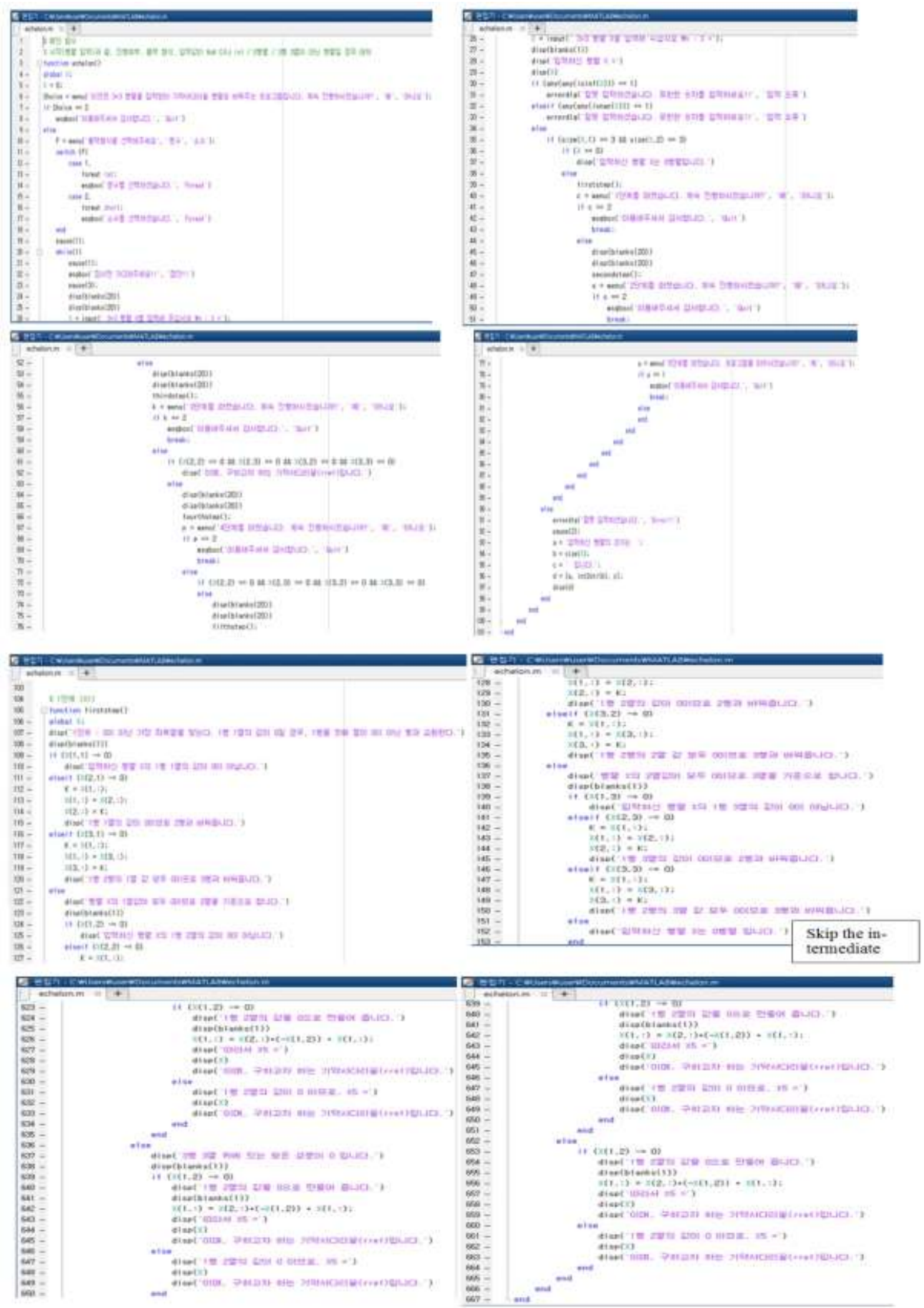

Figure 2. Process Matlab m—file for reduced row echelon form 


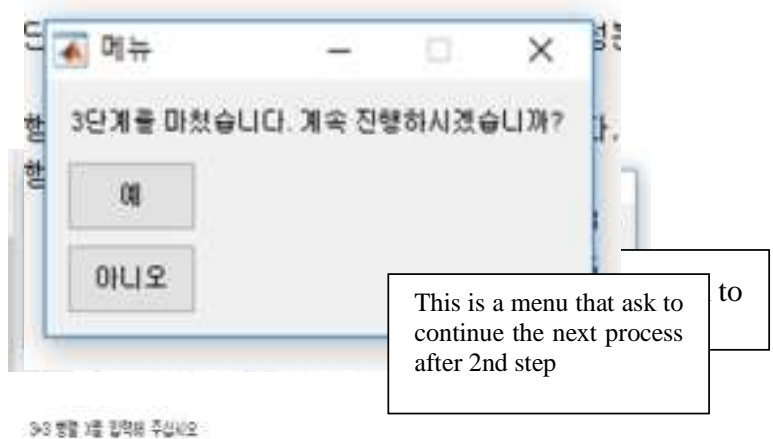

$$
\text { is }=1725: 456.78 \text { Si: }
$$

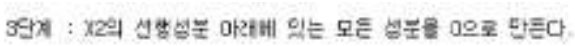

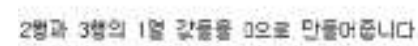

2행, 3 헝 모두 001열 $* 3=$
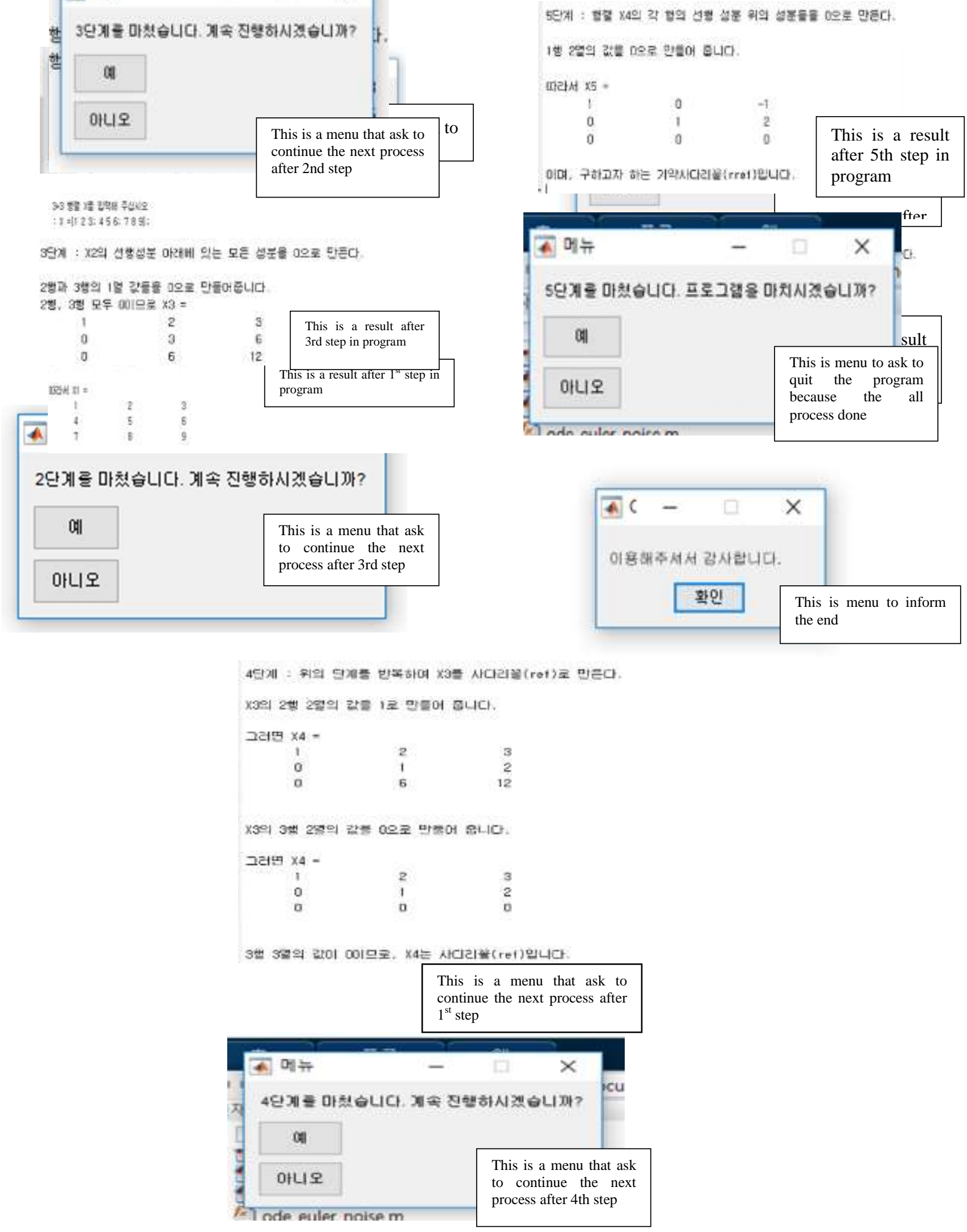

Figure 2. Process Matlab m-file for reduced row echelon form 


\section{Conclusion}

In this study, we have summarized the need and rationale for implementing smart learning in college courses and designed the class model. Here, we introduce a teaching model that combines flipping learning and existing lecture methods. The model presented here, on the contrary, is a model that previously learned the elimination method in the regular class time, and the lessons that were given to the students who later learned MATLAB by presenting additional video material like in the flipped learning. In the existing class model, the students learned the elimination method in linear algebra in the second grade and became the fourth grade and learned the matlab program. Students who did not use the elimination method frequently forget the contents of the elimination method, but after learned programming, learned the elimination method again, and students who did not understand the elimination method were understood through the algorithm. Based on this class model, we want to apply it to future courses to validate learning effects and find ways to activate them. The new generation of digital generation is creative, familiar with cooperation and active. They are already rapidly changing and ready for new education, and education needs a new paradigm to evolve. It is important not only to utilize smart devices, but to create interest and an effective smart learning environment through learner-led customized learning. In particular, we hope that Korea, which has a good digital education infrastructure, will contribute to Korea, the leader of IT technology, as a springboard for smart education.

\section{References}

Addis, K., \& Yigzaw, A. (2018). Investigating English Teachers Perceptions and Practices of TBLT in Three Secondary Schools in Awi Zone. Asian Journal of Contemporary Education, 2(2), 90-121. https://doi.org/10.18488/journal.137.2018.22.90.121

Almeqdadi, F. (2018). The Effects of Using an Interactive Software (GSP) on UAE Students' Attitudes towards Geometry. American Journal of Social Sciences and Humanities, 3(1), 22-28. https://doi.org/10.20448/801.31.22.28

Altunkaya, H., \& Ates, A. (2018). Sources of Reading Anxiety among the Learners of Turkish as a Foreign Language. Asian Journal of Education and Training, 4(3), 161-169. https://doi.org/10.20448/journal.522.2018.43.161.169

Anwar, M. N. (2018). Acquisition of Skills for Listening Comprehension: Barriers and Solutions. International Journal of English Language and Literature Studies, 7(3), 50-54. https://doi.org/10.18488/journal.23.2018.73.50.54

Aremu, J. O. (2018). A Historical Analysis of the Nature, Causes and Impact of the Foreign Debt Crisis in Latin America, 1970-1980. Humanities and Social Sciences Letters, 6(3), 74-83. https://doi.org/10.18488/journal.73.2018.63.74.83

Aremu, J. O., \& Ediagbonya, M. (2018). Trade and Religion in British-Benin Relations, 1553-1897. Global Journal of Social Sciences Studies, 4(2), 78-90. https://doi.org/10.20448/807.4.2.78.90

Asli, H. N. (2018). Has Word of Mouth Advertising in Cyberspace Affected Iran's 2017 Presidential Elections?. Humanities and Social Sciences Letters, 6(3), 84-92. https://doi.org/10.18488/journal.73.2018.63.84.92

Bastug, G. (2018). Examination of Body Composition, Flexibility, Balance, and Concentration Related to Dance Exercise. Asian Journal of Education and Training, 4(3), 210-215. https://doi.org/10.20448/journal.522.2018.43.210.215

Bergmann, J., \& Sams, A. (2012). Flip your classroom: Reach every student in every class everyday. Oregon : ISTE.

Bishop, J. \& Verleger, M. (2013). The flipped classroom: A survey of the research, www.studiesuccesho.nl (2013). Retrieved October 21, 2014. from http://www.studiesuccesho.nl/wp-content/uploads/2014/04/flipped-classroom -artikel.pdf

Caifen, W., Hailun, F., \& Rongrong, C. (2018). The Research on Graduate Students' Understanding of Three Basic Limit Concepts. American Journal of Education and Learning, 3(2), 100-107. https://doi.org/10.20448/804.3.2.100.107

Castro, M. (2018). A Didactic Experiment with Cinema-Portuguese Emigration and Sense of Belonging. Global Journal of Social Sciences Studies, 4(2), 70-77. https://doi.org/10.20448/807.4.2.70.77

Kim, D.R. (2017). Flipped Learning mathematics impact on 숟 university Academic Achievement. Journal of the Korea Convergence Society, 8(6), 209-218. 
Kwon, H.I. (2004). Teachers' Practical Criteria for Evaluation of ICT-Integrated Teaching. The Journal of Educational Information and Media, 10(4), 93-119.

Kwon, S.H., Lee, J., Han, S.Y., \& B, S.H. (2012). A Study on Utilization on e-learning in General Education at University Level. Korean Journal of General Education, 6(1), 9-32.

Lee, S.D.,Park, S.H., Kim, D.K., Kang, S.G. (2010). A Case Study on the Goal-Based Senario Teaching- Learning Method for ICT Application in Education. Journal of Educational Technology, 26(1), 217-250. https://doi.org/10.17232/KSET.26.1.217

Lee, S.G., Park, K.E. (2016). Flipped Learning teaching model design and application. Journal of the Korean Society of Mathematical Education Series E: Communications of Mathematical Education, 30(1), 1-22. https://doi.org/10.7468/jksmee.2016.30.1.1

Seo, B.B., Chea, Y.J., Pan, Y.H., Mai, L.H. (2016). Study on Instrument Model of Smart Learning for Digital Generation : Focusing on the Design. KSDS Conference Proceeding, 116-117. 